\title{
FORMULASI MINUMAN EMULSI FUNGSIONAL MENGGUNAKAN KAROTEN KAPANG ONCOM MERAH
}

\section{[Formulation of Functional Beverage Emulsion Using Carotene of Red Oncom Mold]}

\author{
Felisima H. Kuseno', Abd. Rahman Razak ${ }^{{ }^{\star}}$, Mappiratu ${ }^{1}$ \\ 1 Jurusan Kimia Fakultas MIPA, Universitas Tadulako \\ Jl. Soekarno Hatta Km.9, Kampus Bumi Tadulako Tondo Palu, Telp. 0451- 422611
}

*)Coresponding author: arrazak71@yahoo.com

Diterima 5 Juli 2018, Disetujui 10 Oktober 2018

\begin{abstract}
The research on the formulation of functional beverage emulsion using molds oncom red carotene has been carried out. This study aims to determine the concentration of Tween 80 emulsifier in the formulation of functional drinks red carotene oncom mold and to determine the concentration of carotenoids used to formulate a functional beverage carotene red oncom mold in the form of a stable emulsion. The study was conducted three in phases: isolation of carotene, manufacturing of carotene emulsions beverage and evaluation of carotene. Beverage emulsion stability was determined by the formation of micelles and physical changes in beverage emulsion. The results showed that up to the use carotene of $1000 \mathrm{ppm}$, the emulsion drink was stable until the $15^{\text {th }}$ days and suffered damage on the $21^{\text {st }}$ days.
\end{abstract}

Keywords: Red Oncom mold, carotene, emulsions, functional beverages.

\begin{abstract}
ABSTRAK
Telah dilakukan penelitian tentang formulasi minuman emulsi fungsional menggunakan karoten kapang oncom merah.Penelitian ini bertujuan untuk mengetahui konsentrasi emulgator Tween 80 dalam memformulasi minuman fungsional dari karoten kapang oncom merah dalam bentuk emulsi yang stabil dan untuk mengetahui konsentrasi karoten yang digunakan untuk memformulasi minuman fungsional karoten kapang oncom merah dalam bentuk emulsi yang stabil.Penelitian dilakukan tiga tahap yaitu tahap isolasi karoten, tahap pembuatan minuman emulsi karoten dan evaluasi karoten.Kestabilan minuman emulsi ditentukan dengan terbentuknya misel yang dilihat menggunakan mikroskop dan perubahan fisik pada minuman emulsi. Hasil penelitian menunjukkan bahwa hingga penggunaan 1000 ppm karoten, minuman emulsi stabil sampai hari ke-15 dan mengalami kerusakan pada hari ke-21.
\end{abstract}

Kata kunci : Kapang Oncom merah, karoten, emulsi, minuman fungsional. 


\section{LATAR BELAKANG}

Oncom merah merupakan makanan tradisional yang banyak dibuat dan dikonsumsi masyarakat di Jawa Barat.Produk ini dibuat dari ampas tahu dan campuran bungkil kacang tanah dengan ampas tapioca yang diberi inokulum kapang oncom merah. Menurut Saono et al. (1986), proses fermentasi oncom merah terjadi karena adanya kapang Neurospora sp.

Kapang Neurospora sp mudah dikenal dari konidianya yang berwarna jingga, memiliki miselium yang terdiri dari hifa yang bercabang dan menjulang ke udara, mudah tumbuh pada substrat, dan memiliki waktu generasi yang pendek. Neurospora crassa merupakan jenis Neurospora yang telah banyak diteliti sifatnya. Pigmen warna jingga atau senyawa karotenoid Neurospora crassa tersimpan dalam konidia diproduksi secara intraseluler (Ninet dan Renaud, 1979). Mappiratu (1990) melaporkan bahwa senyawa karotenoid jenis beta karoten dalam Neurospora crass memiliki kadar di atas 50\% berdasar total karotenoid. Karoten kapang oncom merah dapat diproduksi pada medium tongkol jagung.Karoten tersebut mudah dipisahkan dan dapat diawetkan dengan etanol $95 \%$.

Karoten sebagai bagian dari kelompok senyawa karotenoid sangat diperlukan oleh tubuh, baik sebagai pencegahan penyakit maupun sebagai pengobatan. Karoten terutama beta karoten berperan sebagai pencegahan kebutaan dini, kanker payudara dan pencegahan penyakit yang disebabkan oleh kolestrol (Barua dan Olson, 2000). Betakaroten dikonversi dalam tubuh menjadi vitamin A sangat bermanfaat bagi kesehatan mata.

Masalah yang seringkali muncul di negara berkembang, seperti Indonesia adalah kekurangan vitamin A. Untuk penanggulangan hal ini, pemerintah Indonesia melakukan program jangka pendek dan jangka panjang, termasuk program penyuluhan, pemberian dosis tinggi, dan fortifikasi beberapa jenis makanan dengan vitamin $A$ atau provitamin A ( Sirajuddin, 2003).

Selain itu,karoten dalam tubuh dapat berperan mencegah dan menurunkan radikal bebas terutama yang berasal dari lemak atau minyak (Mappiratu, 1990).Karoten termasuk beta karoten dapat diperoleh dari bahan nabati, seperti wortel, semangka, brokoli, dan semua jenis sayuran termasuk tomat dan mikroba.Minuman emulsi yang kaya karoten diperlukan bagi anak - aanak pra sekolah maupun anak - anak yang masih dibangku SD untuk mencegah kebutaan dini. Hal tersebut disebabkan karena bnyak anak - anak yang senang bermain game, di dalam permainan tersebut mata bekera keras dan mengalami kelelahan. Berdasarkan hal ini karoten kapang oncom merah berpotensi digunakan sebagai sumber karoten dalam pembuatan minuman emulsi kaya karoten. 


\section{METODE PENELITIAN}

\section{Bahan dan Peralatan}

Bahan dasar yang digunakan dalam penelitian ini adalah tongkol jagung muda yang diperoleh dari pasar Masomba Palu dan biakan kapang oncom merah yang diperoleh dilaboratorium Penelitian Kimia FMIPA, Jurusan Kimia. Bahan lain yang digunakan mencakup Tween 80, gula pasir, air, etanol $95 \%$, esens jeruk, heksana dan kertas saring.

Peralatan yang digunakan dalam penelitian ini mencakup kompor, dandang, pisau, penjepit jagung, baskom, blender, mikser, dan alat alat gelas yang umum digunakan.

\section{Prosedur Penelitian}

Penelitian ini dilakukan secara bertahap yang terdiri atas tahap produksi karoten, pembuatan minuman fungsional, dan pengamatan stabilitas emulsi.

\section{Produksi Karoten Kapang Oncom Merah}

Produksi karoten dilakukan secara fermentasi menggunakan medium tongkol jagung dan inokulum kapang oncom merah. Pelaksanaan mengikuti cara Mappiratu (1990) yang dimodifikasi sebagai berikut: tongkol jagung mudah yang diperoleh dari pasar Masomba Palu, disortir kemudian disterilkan dengan cara dikukus selama 1 jam. Tongkol jagung yang telah dikukus di simpan diatas rak besi dan dibiarkan dingin, kemudian diinokulasi dengan inokulum kapang oncom merah. Untuk menjaga kelembaban, rak ditutup dengan plastik dan dibiarkan selama seminggu.Konidia kapang oncom merah yang terdapat pada tongkol jagung dipisahkan dengan memakai kuas dan dimasukkan kedalam kertas yang telah ditimbang, selanjutnya ditimbang untuk mengetahui berat konidia kapang oncom merah yang diperoleh.Konidia tersebut selanjutnya diekstraksi menggunakan pelarut heksan hingga semua karoten terekstrak.Ekstrak yang dihasilkan diuapkan secara vakum menggunakan alat rotary vakum evaporator, kemudian disempurnakan dengan gas nitrogen.Ekstrak karoten bebas pelarut ditimbang dan ditentukan rendemennya.

\section{Pembuatan Minuman Emulsi Fungsional}

Pembuatan minuman emulsi karoten dilakukan dengan cara menyiapkan ekstrak karoten (konsentrasi 200 ppm, 400 ppm, 600 ppm, 800 ppm, dan 1000 ppm) diisi dalam gelas kimia $250 \mathrm{ml}$, kemudian ditambahkan emulsifier Tween 80 dengan konsentrasi bervariasi 2,5\%, $5 \%$, dan 7,5\%kemudian ditambahkan sirup 10\%. Sirup simplek yang mengandung sukrosa 66\% (Formularin Indonesia No.488) dan ditambahkan esens jeruk sebanyak $3 \mathrm{ml}$, selanjutnya, di tambahkan air $85 \mathrm{ml}$. Campuran diaduk hingga membentuk emulsi. Minuman emulsi dimasukkan dalam botol yang sudah disterilkan dan disimpan pada suhu ruang untuk diamati perubahan fisiknya. 


\section{Penentuan Stabilitas Emulsi Minuman Fungsional}

Evaluasi minuman emulsi fungsional dilakukan dengan cara minuman disimpan pada suhu ruang dengan melihat perubahan fisik dan diamati stabilitas emulsinya secara visual dan secara mikroskop.

\section{HASIL DAN PEMBAHASAN}

\section{Produk Karoten Kapang Oncom Merah}

Tahap produksi karoten di awali dari proses fermentasi. Pada hari pertama inkubasi tampak benang-benang halus pada permukaan tongkol jagung.Benangbenang halus itu disebut hifa. Kumpulan dari beberapa hifa membentuk kumpulan massa yang disebut dengan miselium dan lebih mudah dilihat oleh mata tanpa menggunakan mikroskop. Pertumbuhan sel merupakan puncak dari aktivitas fisiologis yang saling mempengaruhi secara berurutan. Proses pertumbuhan ini sangat kompleks mencakup pemasukkan nutrien dasar dari lingkungan ke dalam sel. Konversi bahan-bahan nutrien menjadi energi dan konstituen vital sel serta perkembangbiakan. Pertumbuhan mikrobial ditandai dengan peningkatan jumlah dan massa sel (Widjoyo, 2008).

Pelarut yang digunakan untuk melarutkan karoten dari konidia kapang oncom merah pada penelitian ini adalah pelarut n-heksan. Hal ini dikarenakan bahwa $\mathrm{n}$-heksan merupakan pelarut non polar dan efektif sebagai pelarut lemak dan minyak sehingga cocok untuk melarutkan karoten, senyawa karotenoid cenderung larut sempurna apabila pelarut yang digunakan bersifat non polar. Hal ini terjadi karena adanya gaya antar molekul antara senyawa-senyawa yang sejenis cenderung memiliki kekuatan yang sama (Susilowati, 2008). Dilihat dari segi toksisitasnya n-heksan juga kurang berbahaya secara biologis dan harganya relatif lebih murah di bandingkan pelarut yang lain sehingga biaya produksi akan lebih rendah ditinjau dari aspek penelitian skala industri.

Pada perlakuan ini terbukti terdapat karoten pada hasil ekstrak karotenoid dengan adanya warna kuning.Karotenoid adalah suatu pigmen yang berwarna kuning, orange atau merah orange mempunyai sifat larut dalam lemak dan pelarut organik tetapi tidak larut dalam air. Senyawa golongan karotenoid bermanfaat sebagai prekursor vitamin $A$, peningkatan daya tahan tubuh, dan antioksidan (Gross, 1991). Selain itu beberapa golongan karotenoid juga di manfaatkan sebagai pewarna makanan, jumlah total karoten murni yang diperoleh dari penelitian ini adalah 18,04 gram.

\section{Produk Minuman Emulsi}

Penelitian ini menggunakan karoten kapang oncom merah sebagai pengganti minyak dalam emulsi minyak dalam air.Penggunaan karoten pengganti minyak didasarkan atas sifat nonpolar karoten, dimana karoten dan minyak termasuk kelompok lipid. 
Untuk mengetahui pengaruh konsentrasi karoten kapang oncom merah terhadap stabilitas larutan emulsi yang dihasilkan, diterapkan lima tingkatan konsentrasi masing- masing 200 ppm, 400 ppm, 600 ppm, 800 ppm dan 1000 ppm. Stabilisator atau bahan pengemulsi yang digunakan adalah Tween 80 dengan tiga tingkatan konsentrasi masing- masing
2,5\%, 5\% dan 7,5\%. Parameter yang diamati adalah penampakan emulsi melalui pengamatan dengan mikroskop dan pengamatan stabilitas emulsi secara visual. Hasil pengamatan menggunakan mikroskop diperoleh bentuk misel pada stiap penggunaan konsentrasi karoten dan emulsifier (Gambar 1)
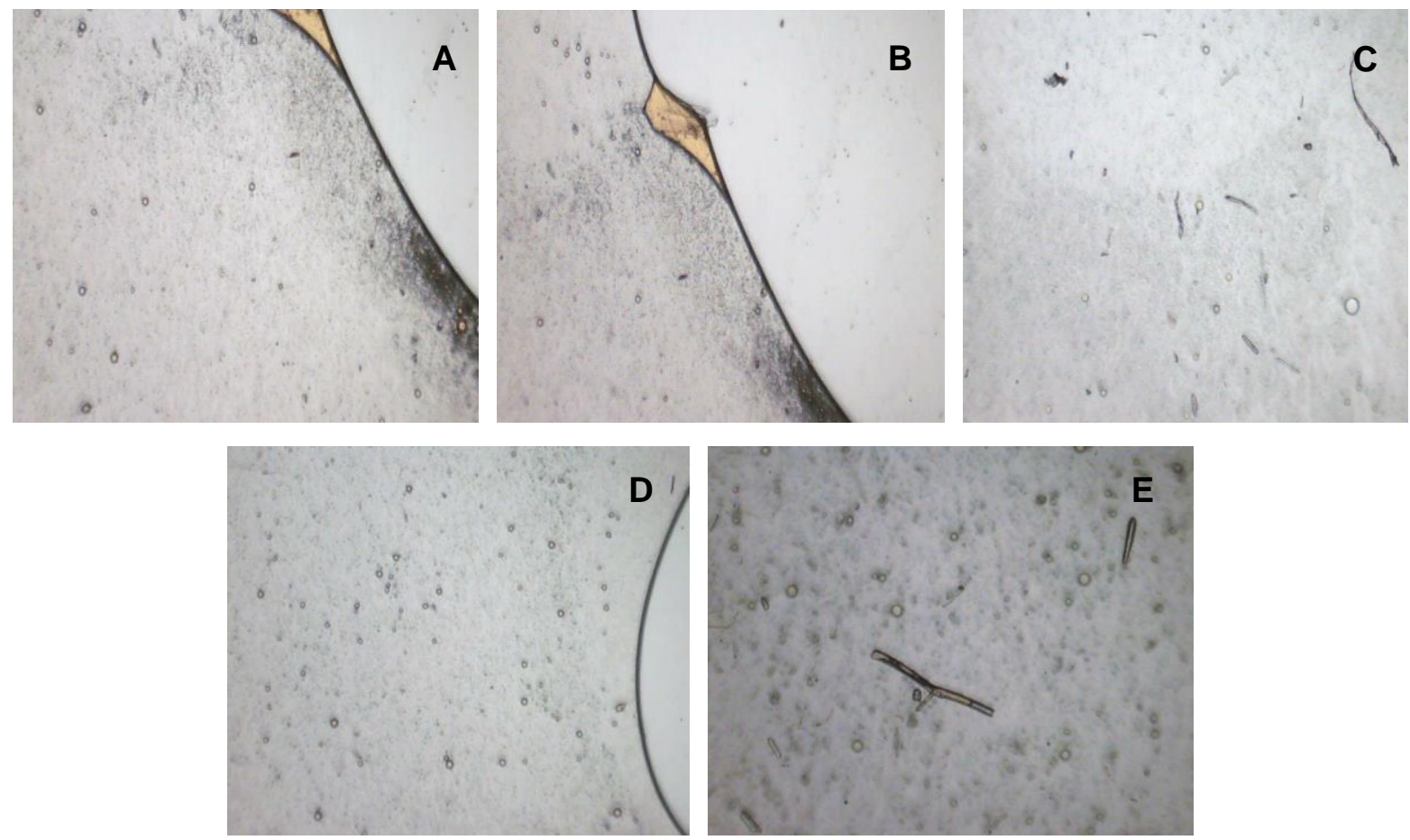

Gambar 1. Penampakan misel emulsi karoten dalam air pada konsentrasi Tween $802,5 \%$ dan konsentrasi karoten 200 (A), 400

(B), 600

(C),800

(D), dan $1000 \mathrm{ppm}$

Pada Gambar 1 terlihat bahwa jumlah misel yang terbentuk mengikuti urutan $\mathrm{A}>\mathrm{B}>\mathrm{C}>\mathrm{D}>\mathrm{E}$ dan misel yang terbentuk pada setiap konsentrasi karoten berukuran kecil. Misel merupakan molekul-molekul surfaktan yang beragregat akibat surfaktan yang ditambhakan berlebih. Keadaan ini terjadi saat permukaan antarmuka menjadi jenuh atau tertutupi oleh surfaktan dan penyerapan surfaktan ke permukaan tidak terjadi lagi. Misel dalam sistem emulsi minyak dalam air berupa kumpulan molekul dengan gugus hidrofilik berada pada bagian luar dan berinteraksi langsung dengan air, sedangkan bagian ekor atau hidrofobik berada pada bagian dalam struktur misel. Misel hanya terbentuk di atas konsentrasi misel kritis 
(CMC) dari surfaktan (Lindman dan Stibs, 1984).

Tingkat stabilitas suatu emulsi sangat dipengaruhi oleh ukuran misel pada fase terdispersinya. Hasil pengamatan stabilitas dan penampakan emulsi pada minuman fungsional terlihat berbeda disetiap minggunya (Gambar 2).
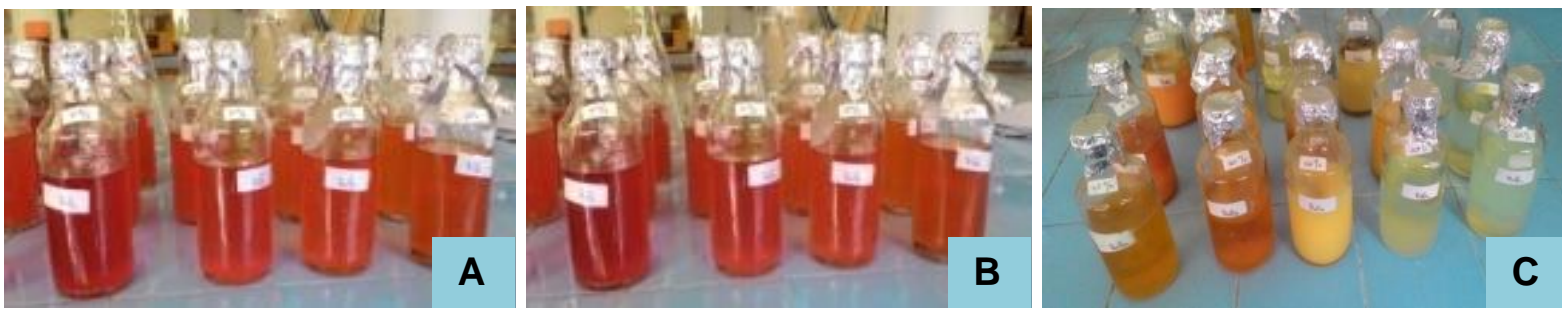

Gambar 2. Stabilitas minuman emulsi dari minggu pertama (A), kedua (B), dan ketiga (C).

Pada Gambar 2, terlihat bahwa pada minggu pertama (A) semua minuman karoten tidak memperlihatkan adanya pemisahan antara air dan karoten. Hal tersebut memberikan indikasi minuman emulsi karoten dalam air stabil hingga tujuh hari penyimpanan. Pada minggu kedua (B), pemisahan karoten dengan air juga belum terjadi atau dengan kata lain sistim emulsi karoten dalam air stabil hingga hari ke lima belas. Pada minggu ketiga (C), memperlihatkan sebagian telah kehilangan warna, sebagian menjadi keruh, dan beberapa diantaranya dalam keadaan jernih atau tidak terjadi pemisahan karoten.

Hilangnya warna pada konsentrasi tween $80 \quad 2,5 \%$ dengan konsentrasi karoten 200 ppm sampai 1000 ppm, disebabkan karena kerusakan karoten selama penyimpanan. Hal tersebut disebabkan karena larutan emulsi yang dihasilkan disimpan pada botol yang tembus cahaya dan di dalam ruangan terbuka. Terjadinya kekeruhan yang diamati pada konsentrasi tween $5 \%$ dan
7,5\% dengan konsentrasi karoten 200 ppm sampai 1000 ppm, disebabkan terjadinya kontaminasi. Dengan demikian, kestabilan emulsi pada hakikatnya tidak berubah pada hari ke dua puluh satu.

Emulsi yang tidak stabil secara termodinamika umumnya disebabkan oleh tingginya energi bebas permukaan yang terbentuk. Pada prosesnya, luas permukaan salah satu fase akan bertambah berlipat ganda, sedangkan seluruh sistem umumnya cenderung kembali kepada posisi stabil atau saat energi bebas sangat rendah, kemudian globula- globula bergabung hingga sistem memisah kembali.

\section{KESIMPULAN}

Dari hasil penelitian yang dilakukan maka dapat disimpulkan bahwa hingga pada konsenrrasi karoten 1000 ppm, minuman beremulsi dapat stabil sampai hari ke-15 dan mengalami kerusakan pada hari ke-21. 


\section{DAFTAR PUSTAKA}

Barua dan Olson. 2000. Analisis Makanan. Yogyakarta: Universitas Gajah Mada.

Frieberg. 1990. Carotenoids in photosintesis. Photochemistry and Photobiology, 63 (3): 257-264.

Gross, J. 1991. Pigmen in Vegetables: Chlorophylls and Carotenoids. New York: Van Nostrand Reinhold.

Lindman, B., dan Stilbs, P. 1984. Surfactants In Solution Volume III ( ed K. L. Mittal and B. Lindman). New York: Plenum Press.

Mappiratu. 1990. Produksi Beta Karoten Pada Limbah Cair Tapioka Dengan Kapang Oncom Merah. [Tesis]. Bogor: FPS-Institut Pertanian Bogor.

Ninet dan Renaud. 1979. Carotenoid as colorant and vitamin $A$ precursor. New York and London: Academic press.

Saono, S., dan W. Budiman. 1986. Penggunaan Beberapa Jenis
Kacang Untuk Pembuatan Oncom, Bulletin Penelitian Teknologi Hasil Pertanian, 20: 12-25.

Sirajuddin. 2003. Shelf life prediction of packaged foods: chemichal, biological, physical, and nutritional aspects. G. Chlaralambous (Ed.). London: Elsevier Publ.

Susilowati. 2008. Isolasi dan Identifikasi Senyawa Karotenoid Dari Cabai Merah (Capsicum annuum L.). [Skripsi]. Malang: Universitas Islam Negeri ( UIN ).

Widjoyo, S. 2008. Teknologi Pengolahan Limbah Untuk Pakan. (ajo66.files.wordpress.com/2008/03/ 6). Diakses tanggal 28 September 2017. 